\title{
Synthesis of Biogenic Silver Nanoparticles From Medicinal Plant And It's Antibacterial Activity
}

\author{
HiralVaghela* ${ }^{1}$, Kokila A. Parmar ${ }^{1}$, Amanullakhan Pathan ${ }^{1}$, Kavita Desai ${ }^{1}$, \\ Jayesh Jadhav ${ }^{1}$ and Rahul Shah ${ }^{2}$ \\ ${ }^{1}$ Department of Chemistry,HNG University, Patan- 384 265, Gujarat, INDIA. \\ ${ }^{2}$ Pacific University, Udaipur-313003, Rajasthan, INDIA.
}

\begin{abstract}
Biological synthesis of nanoparticles from medicinal plant is gaining importance due to its ecofriendliness. The synthesis of metal nanoparticles is a broad research area due to the potential applications for the development of different novel technologies. In our research work, we have described a cost effective and eco-friendly technique for the green synthesis of silver nanoparticles and evaluated their Antibacterial activity. Synthesis and characterization of silver nanoparticles were carried out by using Crateva religiosa plant bark extract as reducing agent as well as capping agent. The Synthesized nanoparticles were characterized with UVVisible spectrometry(UV-Vis), Fourier Transform Infrared Spectroscopy (FT-IR), Scanning Electron Microscopy (SEM) and X-ray Diffraction Spectroscopy(XRD). The antibacterial activity of silver nanoparticles has been Observed.
\end{abstract}

Keyword: Biogenic synthesis,Crateva religiosa bark extract as a reducing agent, $\mathrm{AgNO}_{3}$ salt, Nanoparticles, Antibacterial activity.

\section{Introduction}

Nanotechnology deals with the synthesis of nanoparticles with controlled size, shape, and dispersity of materials at the nanometer scale length and also deals with matter at the scale of 1 billionth of a meter. Also it is the study of manipulating matter at the atomic and molecular scale. Nanoparticles below 10nm range are of great interest due to its potential use in application of electronic, chemical, mechanical industries, drug carriers, sensor as well as in magnetic and electronic materials. Recently fabrication of silver nanoparticles has drawn considerable attention due to their physical and chemical properties and application in biomedicine, antiangiogenic activity against bovine retinal endothelial cells, anticancer activity against lung carcinoma cells [1], controlling HIV infection [2], detection of bacterial pathogens [3] and good catalytic activity [4]. The increasing dimension of microbial resistance has made the management of public health an important issue in the modern world. Although several new antibiotics developed in the last few years, none of them have improved activity against multidrug-resistant bacteria. Therefore, it is important to develop more effective, less toxic (negligible) and ultimate therapeutic strategies to treat gram-negative and gram-positive pathogenic bacteria. Nanoparticles, which have been used successfully for the delivery of therapeutic agents, in diagnostics for chronic diseases and treatment of bacterial infections in skin and burn wounds, are one option.

In this investigation, biological synthesis of silver nanoparticles was carried out using aqueous solution of $1 \mathrm{mM} \mathrm{AgNO}$ and extract of Crateva religiosa Bark and characterized by using UV-visible spectra, Fourier Transform Infra-red Spectra (FTIR), Scanning Electron Microscopy (SEM) and X-ray Diffraction Spectroscopy (XRD).The antibacterial activity has been investigated against gram positive and gram negative bacteria. Biological approaches using microorganisms and plant extract for metal nanoparticles synthesis have been suggested as valuable alternative to chemical method [5-12].

2.1 Chemicals and reagents

\section{Materials And Method}

Silver nitrate was purchased from Himedia.

\subsection{Plant Materials}

Plant (Crateva religiosa)used in the present study was collected from north Gujarat region mounted areas. Fresh bark from the plant was collected and washed several times with double distilled water then dried it in shadow and grind it in mixture. Now $10 \mathrm{gm}$ powder of plant parts (bark) mixed with $100 \mathrm{ml}$ double distilled water. The mixture was boiled for $30 \mathrm{~min}$. at $60^{\circ} \mathrm{C}$. The solution was filtered through Whatman filter paper No.1 and filtrate was stored at $4^{0} \mathrm{C}$ and used as stock solution for Ag NPs synthesis.

\subsection{Synthesis Of Nanoparticles}

For the synthesis of nanoparticles from plant took $20 \mathrm{ml}$ of bark extract of Crateva religiosa, add $30 \mathrm{ml}$ of $1 \mathrm{mM} \mathrm{AgNO}_{3}$ solution, then heated up to $60^{\circ} \mathrm{C}$ with constant stirring using magnetic stirrer with hot plate for 2 
hours. The color change was observed when compared to plant extract without silver nitrate. The color change indicates the synthesis of the silver nanoparticles. Then this colored solution was centrifuged at $12,000 \mathrm{rpm}$ for $20 \mathrm{~min}$. The separated nanoparticles settled at the bottom were collected and washed with double distilled water, then dried in an oven at $60^{\circ} \mathrm{C}$ for two hours. The stabilized powder form of the nanoparticles was stored at $4^{\circ} \mathrm{C}$ for further characterization.

\subsection{Characterization of Silver Nanoparticles}

UV-vis spectroscopy measurements (Shimadzu UV 1800) were carried out at room temperature in the region $800-200 \mathrm{~nm}$ as a function of time of the reaction. FTIR spectroscopy analysis was carried out to identify the biomolecules responsible for the reduction of $\mathrm{Ag}^{+}$ions. X-ray Diffraction (XRD) measurement of the bio reduced silver nanoparticles carried out using ann X'pert pro P analytical X-ray diffractometer instrument. Scanning Electron Microscopic (SEM) analysis was done using Hitachi S-4500 SEM machine. The antibacterial activity of silver nanoparticles was examined against Bacillus pumilus MTCC 9584, Bacillus cereus MTCC 9762, Proteus mirabilis MTCC 9242 and Escherichia coli MTCC 600 using Agar Well Diffusion method and zone of inhibition was measured. The nanoparticles showed zone of inhibition against all the studied bacteria.

\section{Results And Discussion}

Synthesized silver nanoparticles was examined and characterized by using four advanced analysis techniques. These included UV-visible Spectrum analysis, X-ray Diffraction Spectroscopy (XRD), Scanning Electron Microscopic (SEM) and Fourier Transforms Infrared spectroscopy (FTIR).

\subsection{UV-Visible spectroscopy}

Shimadzu uv-1800 (Range 190-1100nm) UV-Visible spectrophotometer was used for the spectrometric analysis to confirm formation of silver nanoparticles. The double distilled water was used as reference for baseline in ranges of 200 to $800 \mathrm{~nm}$. The reaction mixture, Crateva religiosa bark extract with aqueous solution of $1 \mathrm{mM}$ of Silver Nitrate solution changes its color from dark greenish to dark reddish brownish color [Fig.1] which indicates the formation of silver nanoparticles with reduction of $\mathrm{Ag}^{+}$ion to $\mathrm{Ag}^{0}$. The absorption peak is centered around $400-450 \mathrm{~nm}$ for Crateva religiosa synthesized nanoparticles at room temperature $(27 \pm 2$ ${ }^{0} \mathrm{C}$ ). The surface Plasmon band of silver nanoparticles observed at 450nm [Fig. 2], which conform the formation of silver nanoparticles.

\subsection{FT-IR analysis - Fourier transforms infrared spectroscopy analysis}

FT-IR analyses were performed using Bruker Alpha Model (Range 400-4000 $\mathrm{cm}^{-1}$ ). Approximately four $\mathrm{mg}$ of dried powder of silver nanoparticles was mixed with dried $\mathrm{KBr}$ to prepare pellets and subjected to FTIR spectroscopy measurements and scanned using 4000-400 $\mathrm{cm}^{-1}$ IR range [Fig.3].The FTIR characterization is used for identification of biomolecules present in the synthesized Ag nanoparticles. The below [Fig.3] represents the FTIR spectra peaks at $3435.58 \mathrm{~cm}^{-1}, 3099.36 \mathrm{~cm}^{-1}, 2778.24 \mathrm{~cm}^{-1}, 1701.39 \mathrm{~cm}^{-1}, 1376.24 \mathrm{~cm}^{-1}, 546.55 \mathrm{~cm}^{-1}$ and conform the presence of different Functional groups like Alcohol $(\mathrm{O}-\mathrm{H})$, Amine (-NH-), Alkene $(=\mathrm{C}-\mathrm{H}$, $\mathrm{C}=\mathrm{C})$, Alkane $(-\mathrm{C}-\mathrm{H})$, and Carbonyl $(-\mathrm{C}=\mathrm{O})$. This functional groups conform the presence of protein (Amino Acid) which are responsible for the bioreduction of $\mathrm{Ag}^{+}$ion. This evidence suggests that the biological molecules could possibly perform the function for the formation and stabilization of the silver nanoparticles in aqueous medium [13].

\subsection{SEM - Scanning Electron Microscopy}

The silver nanoparticles was examined under Scanning Electron Microscopy (Hitachi S-4500 SEM). Samples for SEM Were Prepared by loading a drop of the nanoparticles solution on the carbon coated copper grid followed by drying under infrared light for $30 \mathrm{~min}$. As a results the particle size and morphological features of the nanoparticles was investigated. The obtained SEM micrographs of AgNPs showed that they are spherical in shape and well distributed in solution with an average size of about $66 \mathrm{~nm}$ in [Fig. 4].

\subsection{XRD - X-Ray Diffractometer}

$\mathrm{X}$-ray diffraction (XRD) measurement of the bio reduced silver nanoparticles determined usingann X'pert pro P analytical X-ray diffractometer instrument. By the annealing at $200^{\circ} \mathrm{C}$, the obtained sharp diffraction patterns of the XRD spectra indicate that the structure of silver is pure crystalline. The figure showed 3 peaks at $2 \theta$ values of $37.76,44.14$ and 65.24 corresponding(hkl) values are 111, 200 and 220 planes which conform the presence of silver nanoparticles [Fig. 5]). All diffraction peaks correspond to the characteristic face centered cubic (FCC) phase [14]. 


\subsection{Antibacterial Activity of Synthesized Silver Nanoparticles}

The antibacterial activity of silver nanoparticles was carried out by agar well diffusion method. The antibacterial activity of silver nanoparticles was examined against Bacillus pumilus MTCC 9584, Bacillus cereus MTCC 9762, Proteus mirabilis MTCC 9242 and Escherichia coli MTCC 600 ( gram positive and gram negative ). Fresh overnight culture of each strain was swabbed uniformly on individual plates which contains sterile Luria Bertani agar and 4 wells were prepared by cup borer with diameter of $6 \mathrm{~mm}$. Then $50 \mu \mathrm{L}$ of purified silver nanoparticles ( in different concentration) poured into each well and commercial antibiotic discs are placed as control. Then incubate it for $24 \mathrm{hr}$ at $37^{\circ} \mathrm{C}$. After incubation zones were observed around the wells and it was measured [Fig. 6]. This experiment was repeated for three times for a good results.
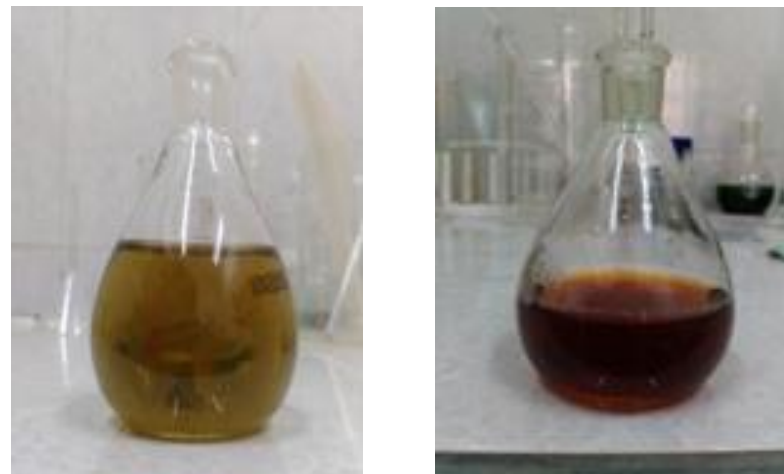

Fig.1 Photographs of (a) bark extract without $\mathrm{AgNo}_{3}$ (b) bark extract $+\mathrm{AgNO}_{3}$ after $2 \mathrm{hr}$ of reaction.

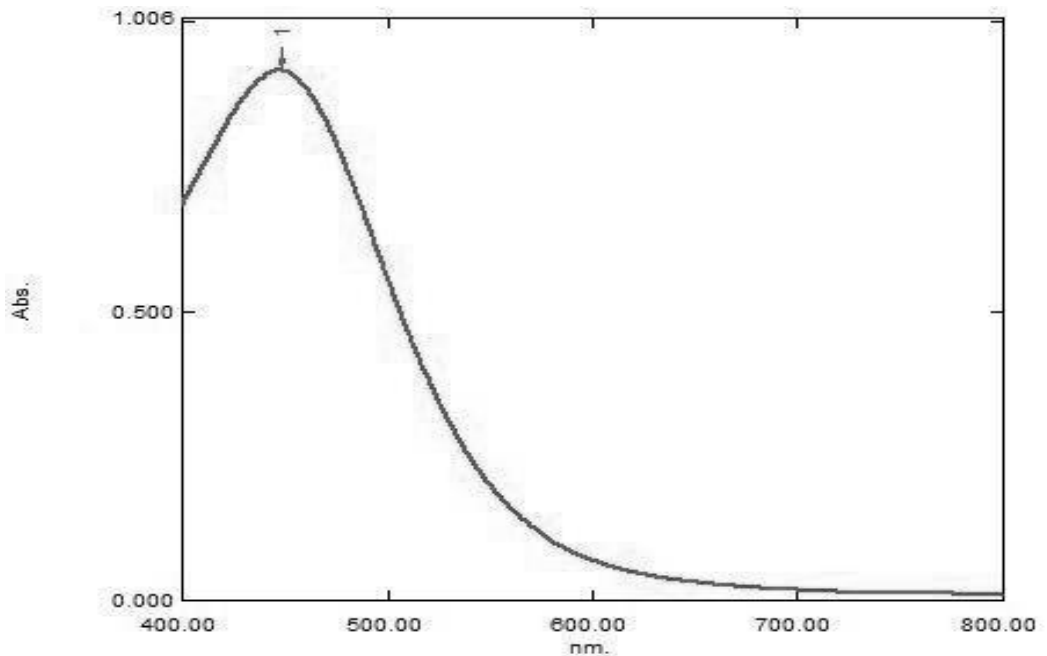

Fig.2 UV-vis spectra of reduction of $\mathrm{Ag}^{+}$ions to $\mathrm{Ag}^{0}$.

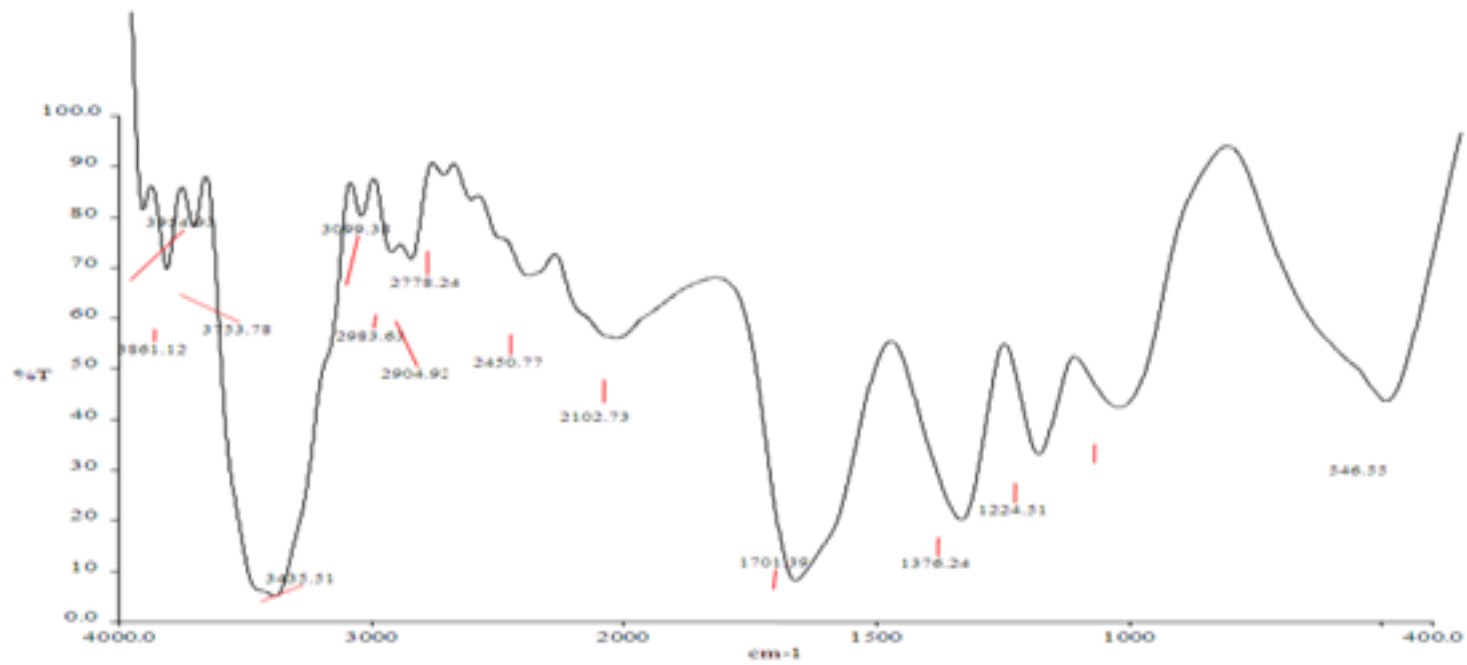

Fig. 3 Showing the FTIR spectrum of synthesised Silver Nanoparticles of Crateva religiosa. 


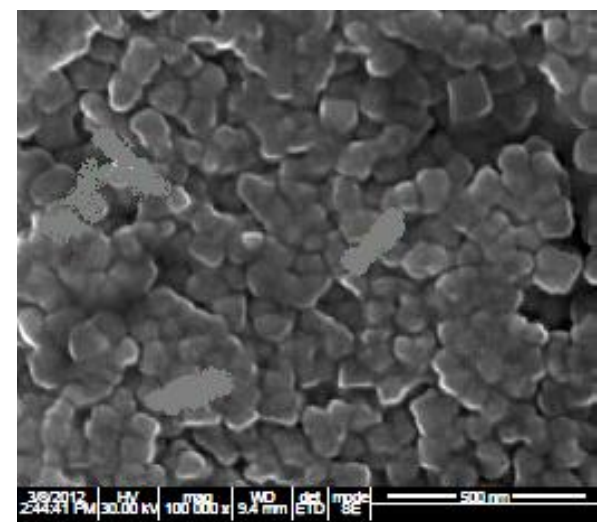

Fig. 4 SEM Image of synthesized silver nanoparticles.

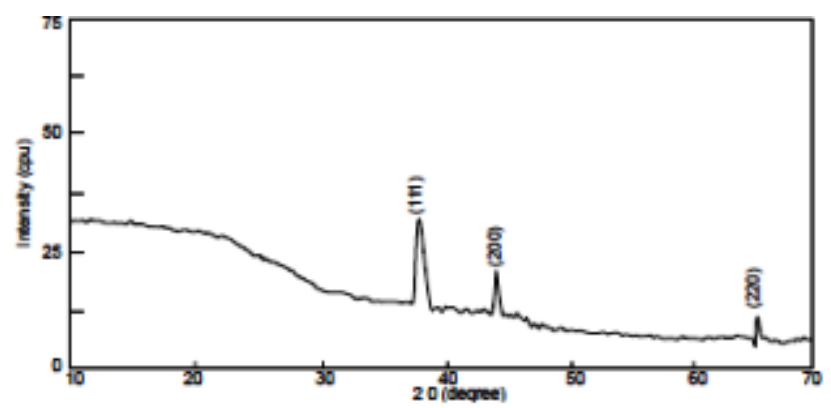

Fig. 5 XRD patterns of synthesized silver nanoparticles.

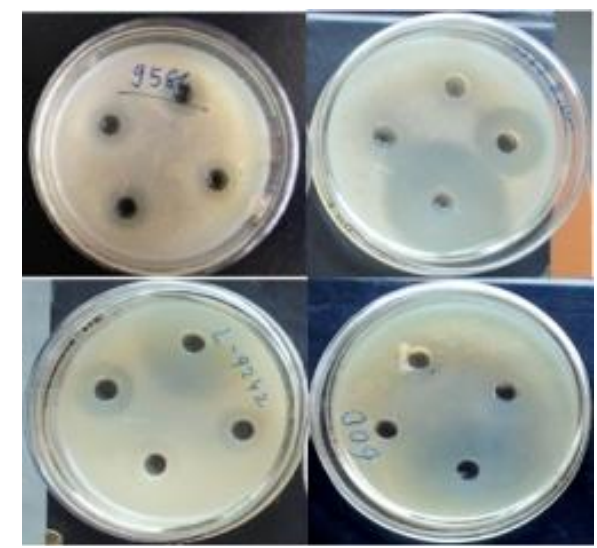

Fig.6 Antibacterial activity of silver nanoparticles against selective bacterial species.

Table :-Antibacterial activity of various concentration of Ag nanoparticles against selective bacterial species.

\begin{tabular}{|c|c|c|c|c|}
\hline \multirow{2}{*}{$\begin{array}{l}\text { Silver } \\
\text { nanoparticles } \\
\text { concentration } \\
\qquad(\mu \mathrm{L})\end{array}$} & \multicolumn{4}{|c|}{ Bacterial species and zone of inhibition in $\mathrm{mm}$. } \\
\hline & $\begin{array}{l}\text { Bacillus } \\
\text { pumilus } \\
\text { MTCC } \\
9584\end{array}$ & $\begin{array}{l}\text { Bacillus } \\
\text { cereus } \\
\text { MTCC } \\
9762\end{array}$ & $\begin{array}{l}\text { Proteus } \\
\text { mirabilis } \\
\text { MTCC } \\
9242\end{array}$ & $\begin{array}{l}\text { Escherichia } \\
\text { coli } \\
\text { MTCC } \\
600\end{array}$ \\
\hline 20 & 08 & 08 & 10 & 09 \\
\hline 40 & 09 & 10 & 11 & 10 \\
\hline 60 & 10 & 11 & 13 & 12 \\
\hline 80 & 12 & 13 & 15 & 16 \\
\hline Ciprofloxacin & $60.0(32)$ & $60.0(33)$ & $60.0(29)$ & $60.0(28)$ \\
\hline Erythromycin & $80(34)$ & $80(34)$ & $80(37)$ & $80(32)$ \\
\hline
\end{tabular}

\section{Conclusion}

In this present investigation, biological synthetic route is selected for the synthesis of silver nanoparticles. The preparation of silver nanoparticles is determined by the reduction of silver nitrate with bioreduction method using aqueous bark extract of Crateva religiosa as the reducing agent without involvement of any toxic chemicals. The metal ions were reduced very rapidly so the reduction of Ag ions was completed within 2 hours. The synthesized silver nanoparticles was confirmed by color change from dark greenish to dark 
brownish and characterized by UV- visible spectroscopy at $450 \mathrm{~nm}$, XRD, FTIR and SEM. Synthesized silver nanoparticles shows particle size between $60-70 \mathrm{~nm}$. The antibacterial activity of synthesized silver nanoparticles was evaluated against pathogenic bacteria and showed good antibacterial activity. Further research is needed in this area to discover the pathways and category of action for silver nanoparticles bacterial metabolism and cell surface.

\section{Acknowledgement}

Author is highly thankful to Rajeev Gandhi Fellowship (University Grants Commission) for financial support and Department of Microbiology, HNG University, Patan, Gujarat for Antibacterial experiments.

\section{References}

[1] K. Paulkumar, G. Gnanajobitha, M. Vanaja, Piper nigrum leaf and stem assisted green synthesis of silver nanoparticles and evaluation of its antibacterial activity against agricultural plant pathogens, The Scientific World Journal, Article ID 829894,2014, 9.

[2] M. Valodkar, P. S. Nagar, R. N. Jadeja, M. C. Thounaojam, R. V. Devkar, and S.Thakore,Euphorbiaceae latex induced green synthesis of non-cytotoxic metallic nanoparticle solutions: a rational approach to antimicrobial applications, Colloids and Surfaces A: Physicochemical and Engineering Aspects, 384 (1-3),2011, 337-344.

[3] J. L. Elechiguerra, J. L. Burt, J. R. Morones, Interaction of silver nanoparticles with HIV-1,Journal of Nanobiotechnology, 3, 2005, article 6.

[4] X. Zhao, L. R. Hilliard, S. J. Mechery, A rapid bioassay for single bacterial cell quantitation using bioconjugated nanoparticles,Proceedingsof the National Academy of Sciences of the United States ofAmerica, 101 (42), 2004, 15027-15032.

[5] D. Bhattacharya, R.K. Gupta, Nanotechnology and potential of microorganisms, Crit Rev Biotechnol, 25,2005, 199-204.

[6] P. Mohanpuria, N.K. Rana, S.K. Yadav, Biosynthesis of nanoparticles: technological concepts and future applications, J Nanopart Res, 10,2007, 507-517.

[7] G. Rajasekhar Reddy, B.M. Antony, N. Nagendra GandhI, Green Synthesis, Characterization and in vitro Antibacterial Studies of Gold Nanoparticles by Using Sennasiameaplant seed aqueous extract at ambient conditions, Asian J. Chem , 25(15), 2013, 85418544 .

[8] N.A. Begum, S. Mondal, S. Basu, R.A. Laskar, D.Mandal, Biogenic synthesis of Au and Ag nanoparticles using aqueous solutions of black tea leaf extracts, Colloids Surf. B, 71(1), 2009, 113-118.

[9] J. Huang, Q. Li, D. Sun, Y. Lu, Y. Su, X.Yang, H.Wang, Y. Wang, W. Shao, N. He, J. Hong, C.Chen, Biosynthesis of silver and gold nanoparticles by novel sundried Cinnamomumcamphoraleaf, Nanotech, 18,2007, 105104-105115.

[10] S.S. Shankar, A. Ahmad, M. Sastry, Geranium leaf assisted biosynthesis of silver nanoparticles, Biotechnol.Prog, 19, 2003, 16271631 .

[11] K.A. Jha, K. Prasad, Green synthesis of silver nanoparticles using Cycas leaf, Inter. J. Green. Nanotech, 1(2), $2010,110-117$.

[12] G. Rajasekhar Reddy, B.M. Antony and Nagendra Gandhi, N. 2,2-Diphenyl-1-Picrylhydrazyl free radical scavenging assay and bacterial toxicity of protein capped silver nanoparticles for antioxidant and antibacterial applications, Asian J. Chem, 25(16),2013, 9249-9254.

[13] S. Mandal, S. Phadtare and M. Sastry, Interfacing biology with nanoparticles, CurrApplPhys, 5, $2005,118-27$.

[14] D.V. Leff, L. Brandt and J.R. Heath, Synthesis and Characterization of Hydrophobic, Organically-Soluble Gold Nanocrystals Functionalized with Primary Amines, Langmuir, 12 (20),1996,4723-4730. 